\title{
Microcredit among Slum Women in Sylhet: A Qualitative Analysis
}

\author{
Priyanka Bhattacharjee \\ Department of Social Work, Shahjalal University of Science and Technology, Bangladesh
}

\begin{abstract}
Poverty is multi-dimensional. However, people naturally want to escape from it. Nowadays, microcredit's didactic evidence is used in many developing countries including Bangladesh to fight against poverty. In a patriarchal society of Bangladesh, women are vulnerable in terms of security, autonomy, self-confidence, and status. Because of gender discrimination, inequality, less control over assets and income, etc. women continue to face chronic forms of poverty. Generally, the well-being of a family greatly depends on the contribution of women rather than men. Slum women have to work within and outside their family. They gather crueler experience in life when compared to their rural counterparts. This is largely because of lack of skill and education; they are confined to employment in petty works. The key purpose of this qualitative research is to examine the extent to which the microcredit programme among slum women in Sylhet has been successful in lifting women out of poverty. Microcredit program was introduced in the slum areas of Sylhet to improve the living conditions, increase awareness level, and empowerment of the poor women. Using purposive sampling techniques and seeking help from NGO workers, 35 semi-structured interviews were conducted with the women microcredit slum dwellers. The findings unravel that most women failed to understand the process and effectiveness of microcredit programs. They took loan for meeting the cash-demand of the male(s) within family. They feel microcredit as a medium to fulfill their emergency requirements. This study found that lack of education, awareness, unwillingness to join other programs of microfinance institutions, pessimistic thinking about microcredit programs, hostile family structure, negligent attitude towards repayment of loan(s), limited investing opportunities, etc. are the main causes that hinders the road to development.
\end{abstract}

Keywords Microcredit, Slum Women, Semi-structured Interviews, Sylhet, Bangladesh

\section{Introduction}

Slum area of the city is the temporary living place of low-income workers who usually migrate from the rural areas. Urban slums are generally excluded from public sector services such as formal education, healthcare, water, and sanitation in addition to borrowing and savings opportunities (Rajja, 2012). Different programs such as vulnerable group feeding, old-aged pension scheme, 100-days work scheme, etc. are available to the rural poor; but fails to extend to the poor living in the slums (Daily Star, 2011). Generally, men and women of the slums are engaged in petty and temporary jobsin the informal sector for running their family(ies). Needless to mention that because of these petty jobs, they earn very little, inadequate for feeding, clothing, and sheltering themselves and their families. Thereby, they fail to save money in any banks or even take loans from formal institutions because of collateral and formal guarantees. Khandker (2000) argues that money savings has an influence to remove poverty; and microcredit programs bear potentiality to stimulate savings because borrowers here make mandatory savings every week and can withdraw it at the end of their membership. Ahmed (2005) seemingly argues that microcredit fulfills the requirement at the doorsteps of the poor at the right time to help them facilitate and start feasible income-generating activities-indeed, a potent agent for promoting social change in prosaic setting(Steele, 1998). Therefore, for promotion of income generating activities, government and non-government organizations (NGOs) such as ASA, Proshika, and Shakti Foundation, etc. have launched microcredit programs in the slum areas (Das, 2003). About three-fourths of the slums received microcredit services from one or more NGOs (CUS, 2005). However, among the poorest section, it is generally the women who remain deprived from the orbit of conventional credit facilities (Younus, 1994). Most women are not recognized as economically productive due to lack of ownership of assets and paid jobs; their contribution to families' well-being are comparatively more than the men; they are less mobile than men, and are more likely to repay 
loans (Rahman, 1999). Hence, in the slum areas, it is the women who are targeted by the microcredit programs. Credit disbursement through the NGOs using integrated approach could bring positive change in the life of the poor-slum-women as well as their communities (Alamgir et al., 2009). Nevertheless, economic, political, cultural, environmental forces and some social factors such as class, gender, caste, religion, age, etc. play important roles in determining the access and control of over resources and these factors are true for the women (Subrahmaynyam, 2000). Many studies have shown that microcredit programs bear positive impact on women by strengthening their economic roles; increase monetary contribution to family well-being; promote social status and self-esteem and reduce poverty at the household, individual and enterprise levels (Chen, 1992; Haesemi and Schuler, 1996; Hussain, 1998; Robinson, 2002; Mann, 2003; Littlefield et al. 2003; Khandker and Pitt, 2005; Abed and Matin, 2007; Swain et al. 2008). Some other studies (Haeshemi, 2001; Rahman and Razzaque, 2000; Ahmed et al., 2006; Matin and Hulme, 2003; Tomlinson, 1995) found that microcredit programs did not reach the poorest of the poor; those borrowers, who could fulfill certain socio-economic requirements, were only given credits. Other studies (Gehlich-Shillabeer, 2008; Daley Harris and Zimmerman, 2009) argued that when borrowers took microcredit for meeting daily consumption needs, it leads to debt and poverty traps. Based on a study in Bangladesh, Khan (1999) concluded that women prefer paid work to self-employment through microcredit. Besides, in the patriarchal society of Bangladesh, women have to maintain norms and values of a society - manage time for active participation of income generating activities alongside other organizational activities (group meeting, skill training, etc.) while compromising their household and outside work obligations. Like all other divisional cities of Bangladesh, living conditions and overall environment of the slums of Sylhet are miserable (Ahmed et al., 2006); people dwelling in these slums are considered as vulnerable (Poverty Reduction Strategy Paper, Bangladesh). This research was conducted on 35-microcredit-women-recipients who are the member of different microcredit organizations for more than 5 -year and live in a slum of Sylhet city. Main objectives of this study are: to probe the overall impact of microcredit on women slum dwellers; to examine the socio-economic aspects of slum women, to investigate as to how the slum dwellers use their loan(s) and to identify the factors that hinder in changing their lives for better.

\section{Review of Literature}

The existence of microcredit has a history of about twenty-three years, but most research reflects mixed picture of the impact (Morduch, 1999) and varies according to social structure. Few scholars argue that for reducing rural poverty in Bangladesh, microcredit institutions were successful
(Hossain, 2002; Yonus, 2001). Slums however, grow usually in areas surrounding urban sprawls largely because of rural-urban migration. The socio-economic conditions of the slums of Bangladesh are much worse when compared to those living in the rural areas (Hossain, 2008). Poverty is more here than the rural areas. In 2005, nearly 35\% of Bangladesh's urban population lived in low-income settlements, or bustees, across six city corporations (CUS et al., 2006). Among the slum dwellers, the status of slum women are vicious both within and outside the home, but their roles as women are much harder when compared to their male-counterparts, especially for those households in acute poverty (Bhattacharjee and Das, 2011). Most microcredit organizations target both economic and social poverty and offer credit particularly to women by forming group but without collateral (Ghalib, 2007; Murray, 2002). In the slums of Hyderabad, India, Banerjee et al., (2009) explored the impact of microcredit on urban slums using a randomized control trial of microcredits offering loans to randomly selected slum areas while withholding these programs from other slums. After a year, the research unraveled no significant effect of access to microcredit on the average monthly per capita expenditure in households, though spending on durable goods and the number of new businesses was on the increase. The impact on other economic outcomes were also found to be mixed, finding differences in spending in durable and non-durable goods based on the household's current ownership of or propensity to open businesses some significant impacts were found on health, education, or women's empowerment. Kobishyn (2009), conducted an impact evaluation of urban microcredit in Hyderabad, and found that women recipients were unable to take major decisions within the home including where to invest the microloan. This finding bears resonance to my research.

Bashar and Rashid (2012) seemingly conducted a comprehensive field survey among 13 districts across Bangladesh to examine the impact of microfinance on urban poor and found that majority of the members who became involved with microfinance institutions since 2005 could improve their economic conditions, however, for $22.52 \%$, the conditions remained unchanged, while for $11.50 \%$, the conditions deteriorated. In 1996, Hulme and Mosley examined 13 microfinance institutions (including Grameen Bank, BRAC, etc.) and found that microcredit was not fruitful for the extreme poor; only non-poor borrowers could do well with microfinance and enjoy significant positive impacts. They concluded that there is a close relationship between the impact of a loan on a borrower's income and their level of income. Similarly, Khandker (2005) investigated 1,800 households in Bangladesh and found marginal improvements for the microcredit borrowers.

Several studies examined influences of microcredit on women's empowerment. Scholars argued that women who participate in microcredit programs not only gains higher-income and consumption including likelihood of 
owning assets, but also gains knowledge about property rights, inheritance, marriage-related laws and dowry, political awareness and plays a larger role in decision-making in purchases within the households (Banu et al., 2001; Hashemi et al., 1996; Kabeer, 2001; Rahman, 1986). Contrary to these, my research findings, which are similar to the findings of Goetz and Sengupta (1994) and Montgomery et al., (1996), shows that microcredit fails to empower women, where women exercised little or no control over microcredits. Therefore, although the unofficial responsibility of loan repayment falls on the men of the household and failure on the part of the men to repay loan in time triggers household conflicts. Few studies suggests that women's membership in microcredit are connected to reduced risk of domestic violence - the threat of losing a loan because of violence alongside the additional support networks could induce husband(s) to become less abusive against their wife(ves) (Hashemi, Schuler \& Riley, 1996; Kabeer, 2001 \& Schuler et al. 1996). However, my research findings suggest that with access to microcredit, when women become economically independent, husband(s) became more violent to take control over their wives (Schuler et al., 1998; Rahman, 1999). Although studies have suggested that microcredit women recipients bear knowledge regarding contraceptives, child-survival methods, etc. (Schuler and Hashemi, 1994; Amin, et al., 1995). However, my findings suggest that women fail to put into practices for varied constraints as discussed below.

\section{Methodology and Ethical Issues}

This exploratory study was conducted on Rakib Mia's slum, Kanishail, Sylhet. For this, I deployed interviews and focus groups discussion (FGD). Alongside, secondary data were collected using different sources such as journal articles and research reports, etc. For collecting primary data, 35 semi-structured interviews were conducted with women recipients living in the slums. Moreover, one FGD was conducted with male persons of this slum and another FGD was conducted amongst the officers of microfinance organizations who run the programs in the slum. At the beginning of this study, information about slums of Sylhet and recipients were collected. Then, Rakib Mia's slum was selected purposively because of its high concentration of rural migrants. Here, almost all the slum dwellers are the recipients of microcredit from different organizations.

For this study, data was collected with the help of loan collection officer of BRAC, Shakti foundation, ASA who are operating their programs in this slum. From their list of recipients, 35 respondents having microcredit membership in organizations for more than five years were selected. Two groups of eight participants were selected for the FGDs.

The access to the respondents was gained through the owner of this slum, mosques and local leaders, group leader and NGO workers. The purpose of the research were explained to them and built a trustworthy relationships $h$ the respondents. There were few loan-defaulters and they suspected me to be from a law-enforcing agency, so they were afraid of and did not want to talk. Majority of the respondents were illiterate; only five were read above class five-poverty was the key reason for their discontinuance. But they are literate to sign their signature. Majority of them were however hesitant to sign the consent form for various reasons, so only oral consents were taken by reading the consent form. They participated in the interviews voluntarily, free from any coercion. They were also free to withdraw their participation at any time. Pseudonyms were used to ensure of their privacy and identities concealed.

After gaining consent, most of the interviews were conducted according to the convenience of the respondents such as at their residence. Each interview took approximately one-to half-hour. Some respondents failed to understand questions, so I had to repeat the questions for clarification; for this reason, the interviews took longer time, which of course hampered respondents' household chores. Male person(s) of some families wanted to interfere in the interview sessions for hiding their defame.

However, the two FGDs took around two hours. Along with me, one of the program group leaders facilitated these FGDs. All the interviews and FGDs were recorded but conducted in Bengali, which were then translated and transcribed into English using verbatim text as far as practicable. The transcripts were checked for accuracy and then coded to develop concepts, themes and sub-themes. Data of interviews and FDGs were also compared for identifying consistencies and contra dictions (if any).

\section{Results}

\section{Socio-demographic Profile of Recipient}

In Rakib Mia's slum, 67.14\% young married women within the age group 25-35 were found as the main recipients of microcredit. Alongside, 5.71\% respondents of receivers were above 45 years. Among all the recipients, majority follows Islamism, but few follow Hinduism. As anticipated, the living conditions of this slum is very poor, all dwelling in rented houses. However, house-type varies according to its rent reflecting the economic status of the tenants. The rent of a thatched (jupri) house is lesser than the rents of semi-pucca and tin-shed houses. While $54.28 \%$ respondents live in tin-shed houses; $14.28 \%$ dwell in jupri house made of polythene, clothes, etc. with no access to cooking gas; so the respondents use straw, leaf, husk, wood, etc. to cook, which are hazardous to respiratory diseases. Although, 8.57\% respondents defecate in open spaces, a few use toilets; however, two or more households share one toilet due to lack of adequate toilets. Majority of the respondents manage their household-waste in the garbage-bin supplied by City Corporation. However, this garbage-bin is placed near the roadside and is not cleaned regularly. Therefore, this slum remains sprinkled with litters. Besides $11.42 \%$ and $20 \%$, 
respondents respectively throw their household-wastes in the open place and in the riverside.91.42percentage slum dwellers live in nuclear families, some separating themselves from their in-laws. Therefore, husband is the head for $62.85 \%$ households. Slum dwellers generally migrate from different areas of Bangladesh primarily because cities promise more jobs and diverse income opportunities than subsistence farming. Here, in this slum, the respondents migrated from Mymensing, Comilla, Kishorgonj and Brahminbaria. Unemployment, landlessness, losing prestige in their previous community, marital reasons were the key causes of the respondents' migration. As majority of the earners in this slum, are engaged in unskilled wage-work without any fixed place of employment or work as self-employed and service-based informal sectors without any fixed establishments of their own, their average monthly income is much below the poverty line; monthly earning being BDT 4000-5000. Since, urban life is very expensive; majority of the respondents spend all their earnings and were able to save very little.

\section{Reasons behind Taking Microcredit}

After the persuasion from microcredit field officers to take loans, majority of the respondents stated that they had taken loans to start a new business; lift themselves out of poverty; earn some extra money and thereby, increase their living standard but majority responded that they failed to understand the program as explained by the field officer.

\section{Wof Utilizing Borrowed Mon}

Although majority of recipients made several plans regarding income-generating activities by using their loans, most women could not execute the plans because of the patriarchal structure of the households; these women failed to take decisions and were considered ineligible to start business for being female. Instead, the household-head took decisions as to how the borrowed money would be spent. In majority of cases, the loan was spent for meeting sudden medical bills, dowries, payment of previous loans, buying valuables such as furniture, cell phones, televisions, etc.

\section{Miserable Life of Loan Recipients}

Because of acute poverty and meager income, already the respondents were sinking in the ocean of problems. The respondents claimed that the loans from the microcredit were another addition to their miseries. Indeed, they were trapped in the loan-burden alongside mounting pressure for repayment from the loan-collection-officers.

\section{Deprived of Enough Food and Nutrition}

It is well documented that food intake behavior of the household members centers round their economic conditions. Because of lower economic conditions, these slum dwellers lives on limited food, which generally contains carbohydrate with protein contents usually absent. Majority seldom managed three meals a day. After accessing microcredit program, they tried to change their conditions, but could not. As one of them said:

"Taking three times meals are not necessary for us as we are habituated with this situation from our childhood. But we feel very unhappy when our children are crying for food, and sometimes we are unable to give them."

Another one said:

"We can somehow manage three-meal for our family. However, nutritional foods-eggs, milk, meat, fish are occasional. In urban areas, there are no vegetable fields from where we can collect some fresh greens for cooking but this is very common in rural areas. We have to depend on buying vegetables, but due to expensive price we are unable to fill the protein demand of our family."

Among the eight participants, of FGD (with household heads), six said that generally women of a family could not manage appropriate meal for all. Female member divide their limited food among their children. Even pregnant women failed to receive sufficient nutrition and calorie intake for their bodies on daily basis.

\section{Health Seeking Behavior of Recipient Women}

Majority of the recipients of this slum chose MAG Osmani Medical College for illness. This is because here they receive treatment at a subsidized cost with some free medicines. However, few recipients attend satellite clinic located at Shimantik for primary care. As one mentioned: "I go to satellite clinic for my antenatal care, although here the doctor's fee is somewhat higher than the Osmani Medical. However, apart from primary care, no other treatments are available here, but the behavior of the doctor and worker is better than Osmani Medical. I heard about this clinic from the group meeting of microcredit."

However, some recipients believing in conventional/indigenous treatments go to the Moulana (religious leader) for panipora (water treatment), telpora (oil treatment), etc. to recover themselves from various diseases. As a reason they have mentioned,

"We are religious-minded, and have great faith on Allah. Everything in the world is running because of his wish. Diseases mainly occur due to curse of God. So, to get cure of diseases taking help from saint is indispensable. People are taking medical treatment; these are costly and have different side effects. But in our treatment there is no side effect. Sometimes it takes long time to be cure. It's a sign of one's endurance towards God."

These respondents are dependent on traditional treatments and bear deceptive ideas about modern methods signaling that they are unaware about modern healthcare. They bear 
misconception regarding children and women's vaccination programs. Because of inadequate numbers of health workers in their area, they subscribed to conventional treatments and. Women recipients know about different birth-control methods. However, some of them have faced serious health problems after using contraceptives for too long. They do not know how they can be cured and the males are careless about this.

During FGD, most household-heads were worried about their child(ren)'s health problems. As they live in dirty environments, their children occasionally suffers from diseases like dysentery, scabies, etc. Even after receiving credits, the recipients' failed to manage good doctors. But added that, they took their child(ren)to the EPI program. However, added that many women recipients had tendencies to go for regular checkups during their pregnancies, as they were more conscious for their unborn babies.

\section{Children's Education}

In every weekly group meetings, the importance of children's education is discussed. However, majority responded that they want to send their children to school, but there are certain cruel realities hindering them to discontinue. As one mentioned:

"My husband invested borrowed money in the business, and suffered huge loss. It is difficult for him to run our family expenses. So, he could not bear the educational expenses of our children; stopped our girl's schooling. However, we tried to run our boy's schooling. It becomes very hard for us to bear his educational expenses too."

"My elder son was a student of class seven in the nearest high school. He was a good student. Because of our economic hardships, we could not bear his tuition fees of that year. I am working as a maidservant and his father is a rickshaw puller. After taking microcredit, we wanted to restart our closed small shop. Then we stopped our son's education and engaged him with our business. As he is an educated boy, we think he can run this business effectively. His father also helps him. We could not continue his education up to higher level, so it was better for him to start business with my borrowed money."

The findings thus indicate that after receiving microcredit, it was necessary to select somebody from the family who could make effective use of the money, even though it could hamper their children's education. The findings also indicate that the recipients viewed that girls' education is less important. That having acquired primary education is more than enough for a girl.

\section{Lack of Decision-Making Power within Home}

Generally, in Bangladeshi society, the male member (usually the household-head) takes decisions about his familial matters. Microcredit opens a new door for the female members to be part of the decision-making within the family. The findings unfold that because of the membership of microcredit organizations, some recipients, although have taken part in the decision-making process within the household ,however, their opinions are not considered as final decisions, but decisions taken by males are considered as final. Most of them said:

"We come to know about different methods of family planning, importance of girls' education, demerits of early marriage, etc. from several group meetings. We can take final decisions on some of the grounds such as, family planning, girls' education issues, etc., apart from these; major decisions are generally taken by the male members of our family."

Others who could not participate in decision-making process said about the barriers of patriarchal society. Male members of their family think women as ignorant and are good only in traditional duties. One said:

"Males generally take decisions on every matter. They think we have no idea regarding outside world, so we could not give our opinion about anything. According to their wish, we had to take microcredit. When they think something will be beneficial for them, they force us to do that thing. They do not consider our opinion. We can attend weekly meetings only with their permission. We have to face physical and mental violence if we do not give value to their decisions."

Only two participants of the FGD said that women could participate in the decision-making process, as they are the member of a family. However, rests of the participants think that women are not eligible to take major decisions, it requires some natural skills which are absent in women. Engaging in microcredit programs does not increase their skill at all for taking major decisions within and outside home. They cannot go anywhere by themselves except for attending group meetings. Even when they go to withdraw loans, a male is with them. Some of them said, male persons often tease them when they go to attend group meetings.

\section{Increasing Rate of Violence against Women}

Although, microcredit is a route to empowerment but it fails to reduce violence within the family as evidenced from the findings. Majority of the recipients had been the victims of physical violence by the husband(s). Indeed, the frequency of violence has increased after becoming a member of microcredit organization, as loan repayment now has become a major issue of facing torture regardless of whether a woman is employed or unemployed. One unemployed women narrated:

"When I asked my husband to pay installment then he refuses. But because of the pressure from the officer and to maintain group solidarity, I have to repeatedly request him to repay loan but my husband becomes violent and tortures me physically. If I have a job, I will not depend on him for money. I am unable to find a job here, as I am unfamiliar with the town."

Similarly, an employed woman said: 
"I am working as a day laborer and earn 150-200 taka daily. To pay weekly installments, I save some money from my earnings but my husband often seize my savings. When I ask him about my money, he tortures me physically."

Another one said:

"I kept my savings with one of my neighbors and when my husband demands this money I refuse to give. But he becomes arrogant as he is alcoholic and beats me cruelly. One day, he even kicked on my abdomen; I fell on the ground and screamed in pain."

These findings unveil that instead of empowering women, microcredit has pushed these women to receiving different forms of violence women seem to have no control over their income, but they withstand the worst of loan repayment.

\section{Recipients' Social Status}

Slum dwellers often hold a lower social status than mainstream society because of their low income, low-level occupation, etc. But after receiving microcredit some of them became chairpersons (group leaders) of a credit recipient group, in some sense increased their income and felt a sense of importance. As one recipient commented: " $A s$ members of the microcredit organization, we have important positions within the group. We get respect not only from the locals but also from the officers of these organizations. We receive invitation for any kind of meetings within our locality, where many important people attend to observe our conditions after receiving microcredit and write about us in the newspaper. I am very happy for this."

However, for most recipients, there were no changes in social status. They believed that those recipients who had significant changes after receiving microcredit might have already enjoyed a better social status. "Everybody praises them for their success and we become futile; nobody care for us. Our social status remains same as before."

The findings thus demonstrate that the recipients whose socio-economic status has improved believe that microcredit is an ineffective tool to reducing poverty.

\section{Victims of Social Problems}

Social problems - early marriage, dowries, birthing more children, etc. are common in the slums. Although, the recipients are aware of these programs, however, regular awareness programs are arranged by different organizations. Nonetheless, reality is very different. Many respondents shared their negative experiences:

"We gave dowry for our sisters/ daughters marriage. But when groom's family came to know that we had taken loan from microcredit, their dowry-demands increased even after marriage. When we refused to meet their demands, they threatened us about our sisters/ daughters' safeties. As a result, we had to pay their demand."
The findings also demonstrate that it is not easy for a woman to practice the knowledge acquired from awareness meetings organized by these organizations simply for their hostile family structure. As one shared her idea on birth control:

"I have learnt about different methods of family planning from group meetings. When I want to control the number of my children, my husband rebukes me in slang languages as he wants more than three children."

Another recipient narrated a bitter incident about her daughter's early marriage:

"I married off my daughter very early because of societal pressure. Now she is very ill because of having more children at such an early age. Officers of microcredit organization tried to convince me to stop this marriage. But I could not."

These findings unravel that slums are the living place of varied social problems, where women are utterly vulnerable. In addition, microcredits have failed to change their socio-economic situations.

\section{Prosaic Purchasing Capacity and No Control over Loan}

Evidently, the purchasing capacities of the recipients have not increased after receiving microcredit. Some respondents even thought that taking microcredit was a grave mistake. Some believed that had they not taken the loan, they could have purchased more things with their extra earnings. Now they have to keep some money for loan repayment every week, thereby, fails to purchase extra things. One recipient said:

"We are very poor, but now we are becoming poorer. It does not matter, how much we can improve economically using microcredit, however, it does matter that we have to repay the loans anyhow. Because of this, we could not purchase anything from our earnings. Price of everything is increasing gradually, but earnings are limited."

There is a close relationship between income and purchasing capacity of an individual. Most of the participants believed that they have been unable to increase their income with microcredit but had to repay the borrowed money so their purchasing capacity has reduced than before. As married women recipients failed to control their loans as it was their husbands who invested it; this increased the possibility of being a credit-defaulter.

\section{Barriers and Difficulties}

\section{Obstacles Face by Women to Becoming a Member of Microcredit Organization:}

Social and cultural barriers embedded in superstitions, patriarchal values and prejudices are the main obstacles in the way to women's development. As in Bangladesh, women 
are treated as inferior to their male-counterparts, some respondents claimed that their husband(s) thought that becoming a member of microcredit would be a threat to their authority over their wife(ves). As one narrated her bitter experience: "Irrespective of many facilities offered by microcredit, my husband did not permit me to engage with such organization because of his fear of losing authority over me. Therefore, he refused the microcredit officer when the officer proposed me to be a member. . However, after some days he permitted me when he needed money in an emergency."

Evidently, people owning property and wealth used to enjoy an easy route to increase their earnings by lending money on high interests. When poor people fall prey to financial emergency with no other alternatives but borrow, they take money on very high interests from usurers. Now microcredit gives credit to the poor and other services. Therefore, the poor are now interested to take credit from them. As a result, microcredits have gradually replaced the usurers' business, but these usurers try to create barriers for the recipients. Some respondents highlighted about this: "The person from whom I used to borrow loan on high interests gave me threat several times after becoming a member of microcredit."

Another commented:

"We are poor and seek comparatively better option for living. So, when I found people are seeking help from microcredits, I became interested to be a member too. However, one of moneylenders tried to motivate me to lend money from him instead of microcredits. He talked to me several times and wanted to lend money at a minimum interest but I came to know about different services of microcredits so, I decided to become a member of such organization. I think this is more secure than borrowing money from usurers."

These findings unravel that recipients of microcredits have faced several barriers not only in becoming members but also in repayment of loans to receiving threats from usurers, yet they dream of changing their lives using microcredits.

\section{Barriers to Using Loans}

Slum women joined microcredit with a hope to transform their lives for better. Nevertheless, lack of education, awareness, unwillingness to join other programs of microfinance, pessimistic thinking about microcredits, hostile family structure, negligent attitude towards repayment of loans, limited investing opportunities, etc. are the key causes that hindered the way to development. One said:

"I knew microcredit will not be able to change our situation, but I took to meet an emergency."

Some respondents have claimed to take microcredits to buy land,; marry their daughter(s), for building house(s), etc. After spending money in such issues, they were unable to receive anything in return, so microcredit became a burden for them. As one shared her mistake:,

"If I had invested money in some productive work, would have been helpful for us. But I did not understand the impact of buying land would be. "

Another one said that her husband wanted to change their present address, as they could not repay loans in time. But as she was reluctant, she was receiving divorce threats. Nonetheless, the research shows that most recipients were unable to invest money in any income generating activities and therefore, very hesitant to participate in other microcredit programs, which calls for policy implications.

\section{Concluding Remarks and Policy Implications}

The existing social structure of the slum does not allow women's full participation in economic activities. However, to seek family welfare they are compelled to seek microcredits, especially when the husband had failed to run the family. Because of the patriarchal structure, most women had no voice to decide on how the loans would be spent. . Research also unfolded that regardless of whether, they could repay loans, and some recipients took several loans from different microcredits and then changed their address, which made it difficult for the officers to trace them. Most recipients however thought of microcredit as a source to meet their needs and a kind of welfare service for the poor. This is largely because of lack of education. Moreover, they are unaware about their rights and responsibilities.

Microcredit officers told that it was indeed very hard to run programs in the urban areas compared to rural areas. This is because of high mobility of the recipients living mostly in rented houses. Other factors contributing to barriers are lack of social bonding among group members, a predominance of non-agricultural occupations, prevalence of local leaders or mastans in the slums, competitive nature of relationship among people of slums, etc. Besides, some recipients who took several loans from different organizations, which made them more vulnerable. Therefore, coordination is necessary among all these organizations running microcredits in the slums. They need to work together on behalf of their members' interests such as, legal advice system for protecting women's rights. They should launch several programs and engage women in economic activities not individually but collectively. Media should air the success story of slum recipients, from which other women gain inspiration. Government should take different policy for slum dwellers, because these women have much potential. Indeed, microcredit should be operated with services and perhaps in a more congenial atmosphere, a road through which they contribute to the development of the country. 


\section{REFERENCES}

Ahmed, Dr Salehuddin. (2005). "Microcredit in Bangladesh: Achievements and Challenges". PKSF, Dhaka, Bangladesh.

Ahmed, Mushtaq; Hoque, M. A.; Sarkar, M. S. K. A.; Chowdhury, M. A. I.; Begum, A. (2006). "SOCIO-CULTURAL EVALUATION OF SANITATION HYGIENE IN SYLHET CITY OF BANGLADESH". ARPN Journal of Engineering and Applied Sciences, 1(3).

Alamgir, M. S.; Jabbar, M. A.; Islam, M. S. (2009). “Assessing the livelihood of slum dwellers in Dhaka city", Journal of Bangladesh Argil. Univ. 7(2): 373-380.

Amin, R. et al. (1995). "Poor Women's Participation in Credit-Based Self Employment: The Impact on Their Empowerment, Fertility, Contraceptive Use and Fertility Desire in Rural Bangladesh”. Pakistan Development review. 34(2) 93-119.

Banerjee, A., E. Duflow, R. Glenerster and C. Kinman. (2009). "The Miracle of Microfinance? Evidence from a Randomized Evaluation". Department of Economics, Massachusetts Institute of Technology working paper, May.

Bashar, Toriqul and Rashid, Salim. (2012). "Urban poverty and urban micro finance". Journal of the Asia Pacific Economy, 17(1). 151-170.

Bhattacharjee, Rakshit and Das, Tulshi Kumar. (2011). "The role and Status of the Women Living in Slum". LAMBERT, Germany.

Centre for Urban Studies,. (2006). "Slums of Urban Bangladesh: Mapping and Census", NIPORT, Dhaka.

Daley-Harris, S and Zimmerman, J. (2009). "Microfinance does not usually serve the very poor, for whom it can represent a route into debt rather than a way out of poverty." Enterprise Development and Microfinance, 20, (2), 79-85.

Das, Dr. Tulshi Kumar. (2003). "Culture of Slum Dwellers: A Study of a slum in Dhaka". Boipatra, Dhaka.

Gehlich-Shillabeer, M. (2008). "Poverty alleviation or poverty traps? Microcredits and vulnerability in Bangladesh." Disaster Prevention and Management, 17, (3), 396-409.

Goetz,A.M. and R, Sen Gupta. (1994). "Who Takes the Credit? Gender, Power and Control over loan Use in Rural Credit Programs in Bangladesh”. World Development, 24, (1), 45-63.
Hossain, Shahadat. (2008). "Rapid Urban Growth and Poverty in Dhaka City". Bangladesh e-journal of Sociology, 5, (1).

Hulme, D. and Mosley, P. (1996). "Finance against Poverty". Routledge, London.

Khan, MR. (1999). "Microfinance, wage employment and housework: A gender analysis." Development in Practice, 9, (4), 424-436.

Khandker, M. (2000). "Does micro credit empower women? Evidence from Bangladesh." World Bank Policy Research working paper, No. 2998.

Matin, I and Hulme, D. (2003). "Programs for the poorest: Learning from the IGVGD program in Bangladesh." World Development, 31 , (3), 647-665.

Mohammad, Rajja. (2012). "Rights of people living in informal or slum settlements in Bangladesh". Dhaka.

Montgomery, R., Bhattacharya, D., Hulme, D. (1996). "Credit for the poor in Bangladesh". Routledg, London.

Pitt, M. M. et al. (1999). "Credit Programs for the Poor and Reproductive Behavior in Low-income Countries: Are the Reported Causal Relationships the Result of Heterogeneity Bias", Demography. 36(1).

Rahman, A.(1986). "Impact of Grameen Bank on the Situation of Poor Rural Women". BIDS working paper, No.1, Dhaka.

Rahman, A. (1999). "Micro-credit Initiatives for Equitable and Sustainable Development: Who Pays?" World Development, 27(1): 67-82.

Rahman, A and Razzaque, A. (2000). "On reaching the hard core poor: Some evidence on social exclusion in NGO programs." Bangladesh Development Studies, XXVI (1), 1-36.

Steele, Fiona; Amin, Sajeda and Naved, Ruchira T. (1998). "The impact of an Integrated Micro credit Program on Women's Empowerment and Fertility Behavior in Rural Bangladesh". Population Council, New York.

Subrahmanyam, A. (2000). "Case of women who carry the double burden of gender and poverty." www.humiliationstudies.org.

Yunus, M. (1994). “Credit for Self-Employment: A Fundamental Human Right.” Grameen Bank, Dhaka. 